\title{
Enhanced coagulant extraction from Jatropha curcas in aqueous solutions and its application in turbidity removal
}

\begin{abstract}
In this study, the effect of the extraction medium on the properties and efficiency of biocoagulant, extracted of Jatropha curcas $(\mathrm{Jc})$, in turbidity removal from aqueous solutions has been investigated. The optimized values of $\mathrm{NaCl}$ concentration (i.e., $\mathrm{NaCl}$ ), solution $\mathrm{pH}$ and solution temperature were identified to improve the extraction of the coagulant. The optimized conditions were associated with an optimum coagulant dosage and a maximum turbidity removal from the synthetic aqueous solutions. The highest turbidity reduction was achieved with the coagulant extracted at a solution $\mathrm{pH}$ of 10 and an extraction temperature of $60^{\circ} \mathrm{C}$ ( $\mathrm{pH} 10 / 60^{\circ} \mathrm{C}-\mathrm{Jc}$ press cake). Under these conditions, the coagulant dosage required was reduced by $80 \%-90 \%$, depending on the coagulation $\mathrm{pH}$. At the coagulation $\mathrm{pH}=6$, the $\mathrm{pH} 10 / 60^{\circ} \mathrm{C}-\mathrm{Jc}$ press cake well reduced the turbidity by $85 \%$. However, the distilled waterbased extract failed to lower the turbidity. Several analytical techniques were employed to characterize the nature of the active components derived from Jc. SDS-PAGE electrophoresis showed that Jc extract was mainly made up of proteins with molecular weights between 20 and $35 \mathrm{kDa}$. The optimized extraction conditions significantly improved the efficiency of this promising bio-derived coagulant in turbidity reduction. This study demonstrates the potential employability of these enhanced bio-coagulants. This can be a step ahead in helping with the development of sustainable processes in (waste)water treatment, particularly in tropical regions, for example, Malaysia with an abundant access to Jc.
\end{abstract}

Keyword: Jatropha curcas; Natural coagulant; Water treatment; Biomass; Protein; Turbidity removal 